\title{
Life in the desert: habitat spatial complexity, gene flow, and functional connectivity in Ivesia webberi
}

\author{
Israel Borokini ${ }^{1}$, Kelly Klingler ${ }^{2}$, and Mary Peacock ${ }^{1}$ \\ ${ }^{1}$ University of Nevada Reno \\ ${ }^{2}$ University of Massachusetts Amherst
}

June 24, 2021

\begin{abstract}
Habitat protection, by itself, is not sufficient to conserve range-restricted species with disjunct populations. Indeed, it becomes critical to characterize gene flow among the populations and factors that influence functional connectivity in order to design effective conservation programs for such species. In this study, we genotyped 314 individuals of Ivesia webberi, a United States federally threatened Great Basin Desert perennial forb using six microsatellite loci, to estimate genetic diversity and population genetic structure, as well as rates and direction of gene flow among 16 extant I. webberi populations. We assessed the effects of Euclidean distance, landscape features, and ecological dissimilarity on the genetic structure of the sampled populations, while also testing for a relationship between I. webberi genetic diversity and diversity in the vegetative communities. The results show low levels of genetic diversity overall $(\mathrm{He}=0.200-0.441 ; \mathrm{Ho}=0.192-0.605)$ and high genetic differentiation among populations. Genetic diversity was structured along a geographic gradient, congruent with patterns of isolation by distance. Populations near the species' range core have relatively high genetic diversity, supporting a central-marginal pattern, while peripheral populations have lower genetic diversity, significantly higher genetic distances, higher relatedness, and evidence of genetic bottlenecks. Genotype cluster admixture results support a predominant west to east gene flow pattern for populations near the species' range center, as well as smaller genotype clusters with a narrow north to south distribution and little admixture, suggesting that dispersal direction and distance vary on the landscape. Pairwise genetic distance strongly correlates with actual evapotranspiration and precipitation, indicating a role for isolation by environment, which the observed phenological mismatches among the populations also support. The significant correlation between pairwise genetic distance and dissimilarity in the soil seed bank suggest that annual regeneration of the floristic communities contributes to the maintenance of genetic diversity in I. webberi.
\end{abstract}

\section{Hosted file}

Borokini et al landscape genetics ms.docx available at https://authorea.com/users/421649/ articles/527586-life-in-the-desert-habitat-spatial-complexity-gene-flow-and-functionalconnectivity-in-ivesia-webberi 